\title{
Comparison of the Effectiveness of Yoga and Psychotherapy group Therapy Based on Acceptance and Commitment on Fatigue and Quality of Life of Multiple Sclerosis Patients
}

\section{Raheleh Rezaian Langroudi ${ }^{1}$, Masoud Ghiasian ${ }^{2}$, Mehdi Roozbehani ${ }^{* 3}$, Farshid Shamsaei ${ }^{4}$}

1. PhD Student in Psychology, Department of Psychology, Borujerd Branch, Islamic Azad University, Borujerd, Iran

2. Assistant Professor, Department of Neurology, Faculty of Medicine, Hamadan University of Medical Sciences, Hamadan, Iran

3. Assistant Professor, Department of Physical Education (Motor Behavior), Borujerd Branch, Islamic Azad University, Borujerd, Iran

4. Associate Professor, Department of Nursing, School of Nursing and Midwifery, Hamadan University of Medical Sciences, Hamadan, Iran

\section{Article Info}

Received: 2020/03/29;

Accepted: 2020/05/19;

Published Online: 2020/08/19

10.30699/ajnmc.28.4.62

Original Article

Use your device to scan and read the article online

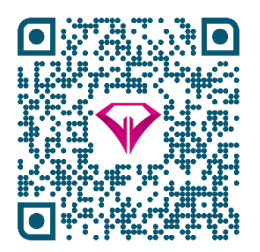

\section{ABSTRACT}

Introduction: Multiple sclerosis (MS) is a chronic and debilitating disease of the central nervous system. Chronic illness and lack of definitive treatment reduce all aspects of physical and social functioning and thus reduce quality of life. The aim of this study was to compare the effectiveness of a group of yoga and psychotherapy group exercises based on acceptance and commitment to fatigue and quality of life of patients with MS.

Methods: In the present quasi-experimental study (pre-test-post-test design), 60 women with MS referred to the Neshat Clinic in Hamadan were selected randomly, considering entry criteria and then divided into two equal groups of yoga exercises and acceptance and commitment-based therapy groups (both 12 sessions each). Data were analyzed using independent t-test, Chi-score and Fisher's exact test, analysis of covariance and LSD with 95\% confidence level by SPSS software version 22 .

Results: The results showed that compared to group psychotherapy based on acceptance and commitment, yoga group demonstrated $-5.29 \pm 0.69$ units of reduction in the fatigue score and $8.39 \pm 1.11$ units of decrease in quality of life score which was statistically significant $(P$ $<0.001)$.

Conclusion: It can be concluded that yoga and group psychotherapy based on acceptance and commitment reduce fatigue and increase the quality of life of patients with MS. It is effective that these results can promise a new development in interventions, so that in addition to drug treatment, complementary therapies can be used to reduce the complications of the disease.

Keywords: Fatigue, Acceptance and Commitment Psychotherapy, Quality of Life, Multiple Sclerosis, Yoga

Corresponding Information:

Mehdi Roozbehani, Assistant Professor, Department of Physical Education (Motor Behavior), Borujerd Branch, Islamic Azad University, Borujerd, Iran. Email: Mehdi.roozbahani@gmail.com

Copyright $\odot$ 2020, This is an original open-access article distributed under the terms of the Creative Commons Attribution-noncommercial 4.0 International License which permits copy and redistribution of the material just in noncommercial usages with proper citation.

How to Cite This Article:

Rezaeian Langroodi R, Ghiasian M, Roozbehani M, Shamsaei F. Comparison of the Effectiveness of Yoga and Psychotherapy group Therapy Based on Acceptance and Commitment on Fatigue and Quality of Life of Multiple Sclerosis Patients. Avicenna J Nurs Midwifery Care. 2020; 28 (4): 62-72 


\section{مقايسةُ اثربخشى تمرينات يوكا و رواندرمانى گروهى مبتنى بر يذيرش و تعهد بر خستخَى و كيفيت زندكى بيماران مولتييلاسكلروزيس}

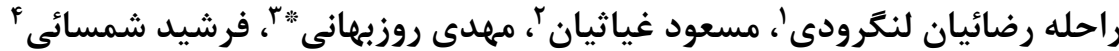

$$
\begin{aligned}
& \text { ( · دانشجوى دكترى روانشناسى، كروه روانشناسى، واحد بروجرد، دانشكاه آزاد اسلامى، بروجرد، ايران }
\end{aligned}
$$

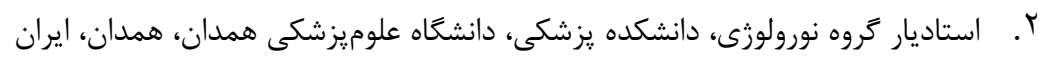

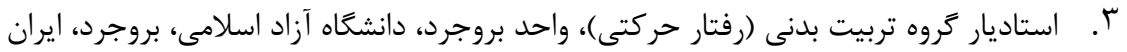

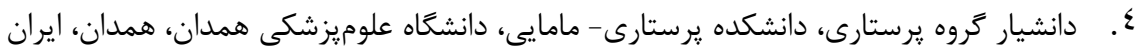

\begin{tabular}{|c|c|}
\hline جكيده & اطلاعات مقاله \\
\hline 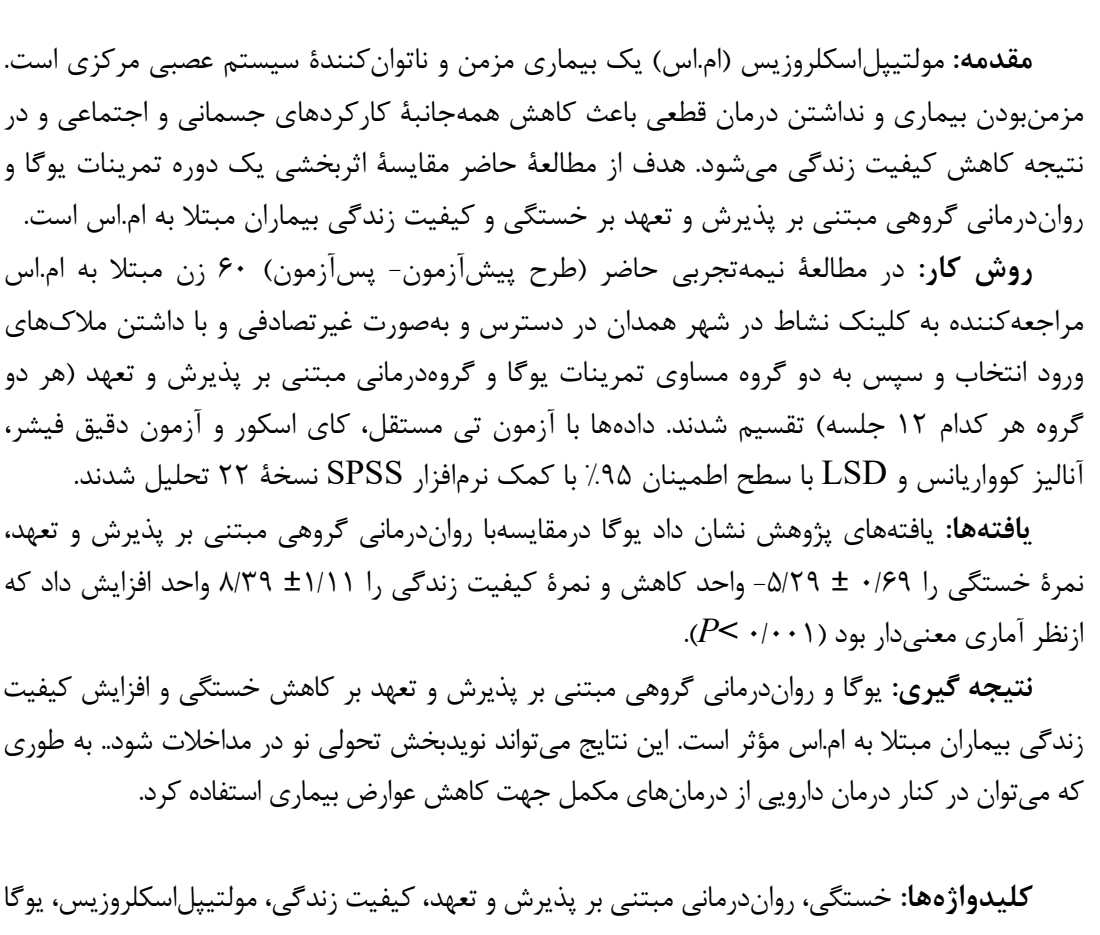 & 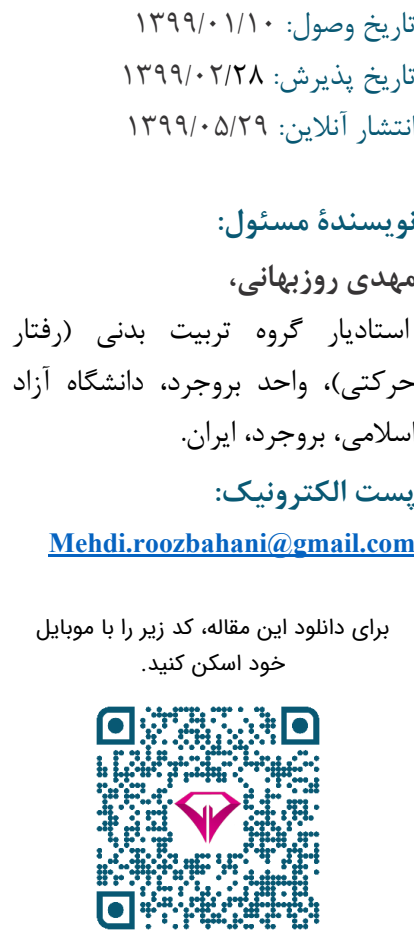 \\
\hline
\end{tabular}

اگرجه اين بيمارى در كودكان و نوجوانان شايع نيست و تشخيص اين بيمارى در اين سنين نيز دشوار است اما تاكنون

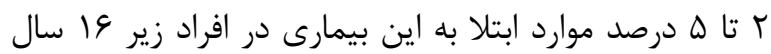

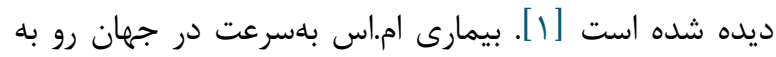

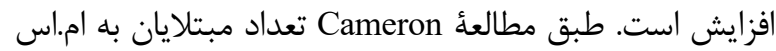

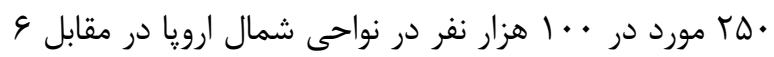

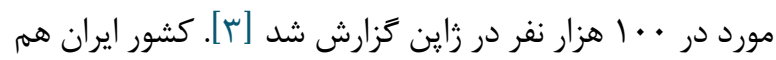
از اين قاعده مستثنى نيست اخر جه آمار دقيقى از تعداد مبتلايان

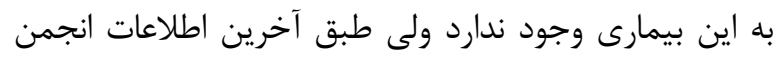

مولتيِلاسكلروزيس (ام.اس) يكى از شايعترين بيمارىهاى سيستم عصبى مركزى است كه باعث دركيرى و تخريب غلاف ميلين در مغز و طناب نخاعى مىشود [1]]. در اين بيمارى مرى

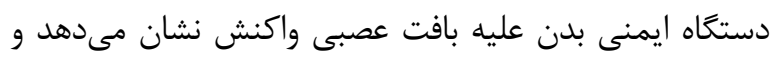
باعث تخريب ميلين و در نهايت اسكلروز (تصلب، سختى) در

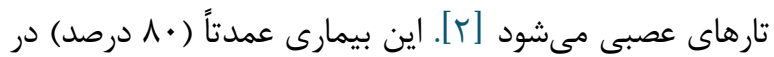

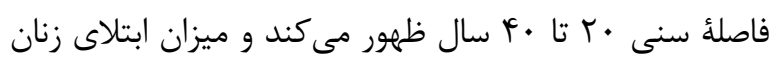

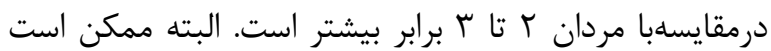
افراد در هر سن و با هر جنسيتى به اين بيمارى مبتلا شوند [س]. 


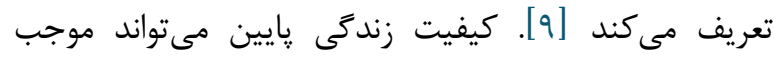

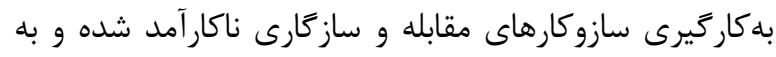

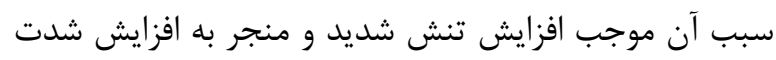

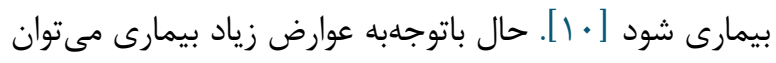

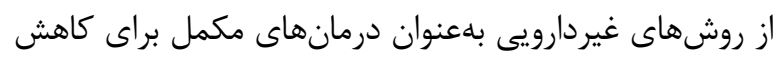

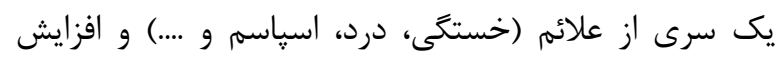

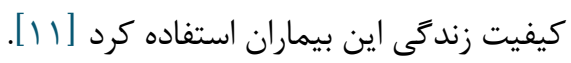

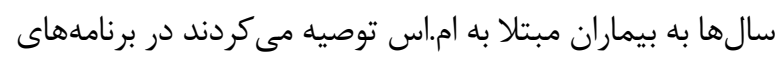

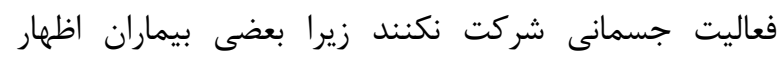

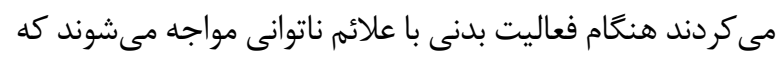

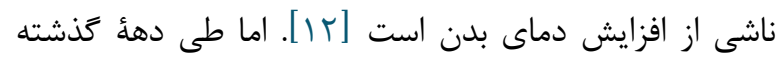

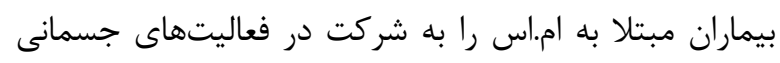

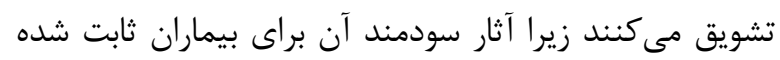

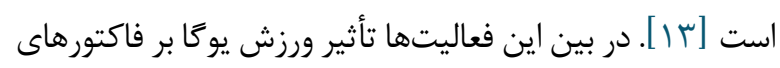

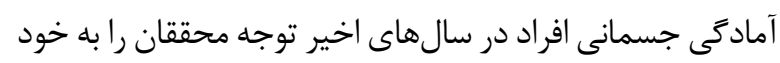

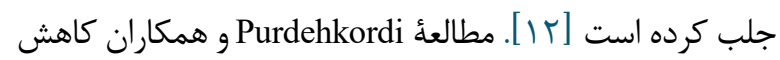

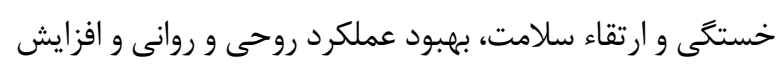

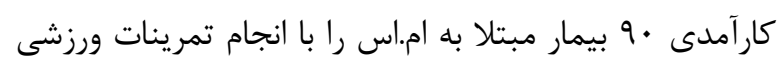

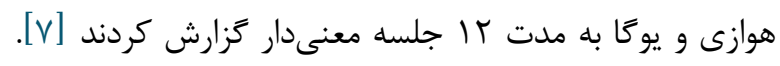

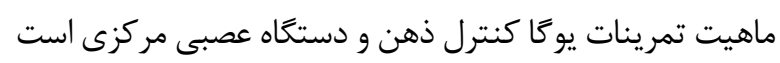

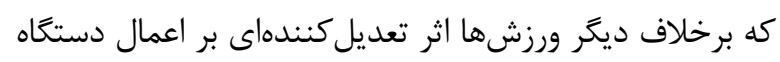

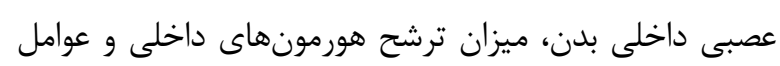

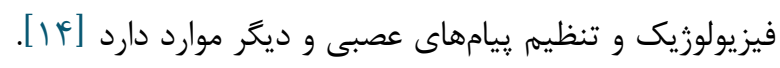
طى فعاليتهاى ورزشى فرايند از دست رفتن ميلين تغيير

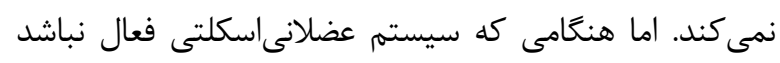

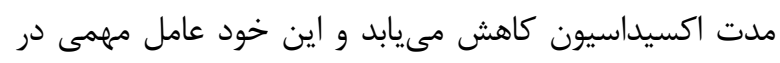

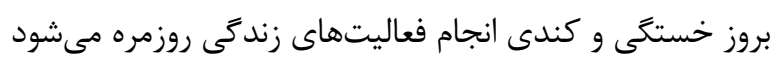

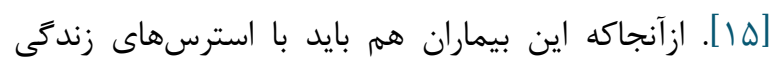

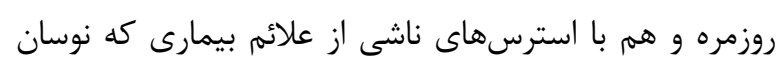

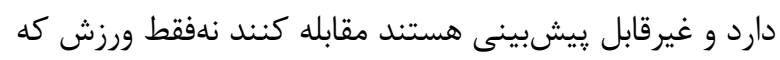

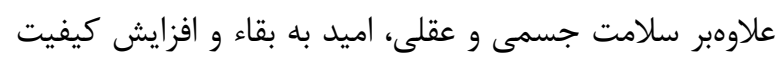

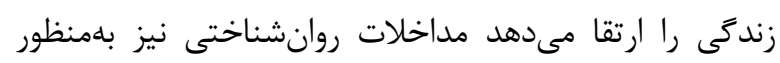

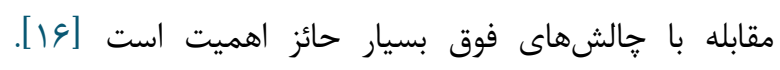

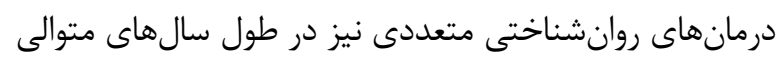

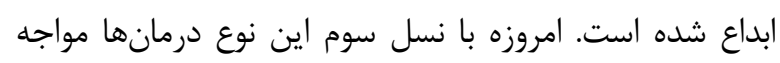

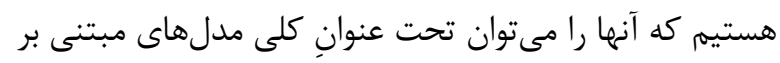

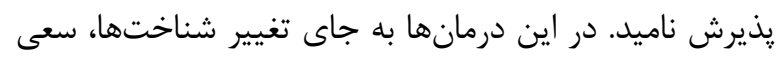

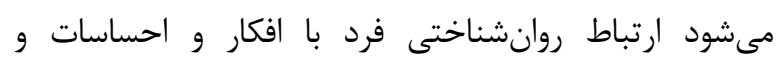

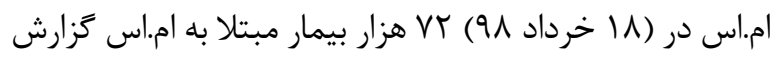

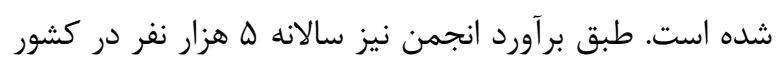

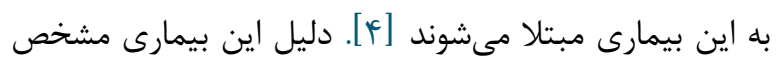

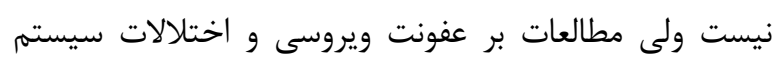

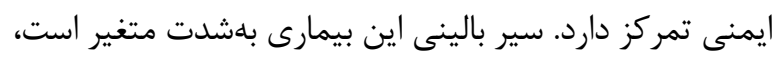

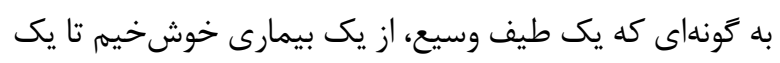

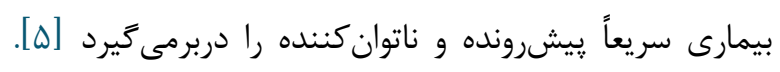

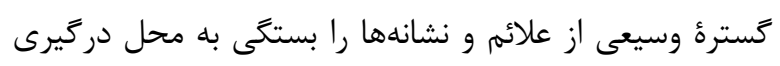

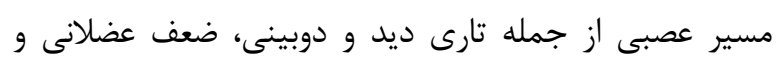

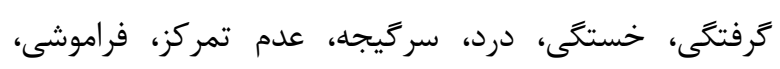
نارسايى عملكرد روده و مثانه، اختلال در تعادل و هماهنئي و و ...

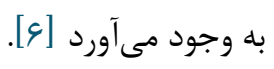
يكى از شايعترين و ناتوان كنندهترين علائم اين بيمارى خستخى التى

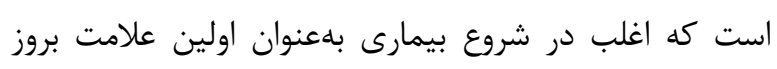

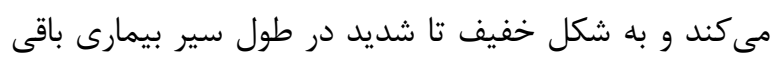

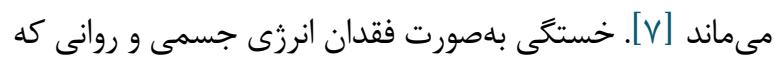

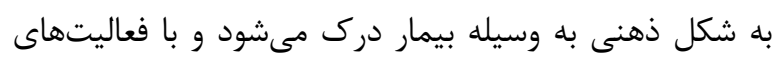

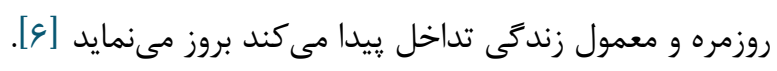

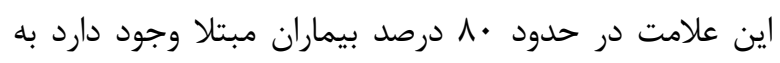

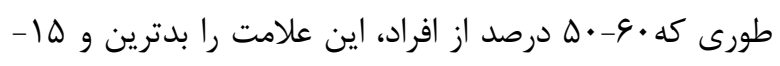

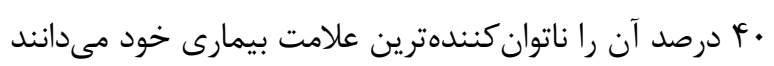

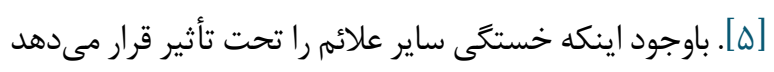

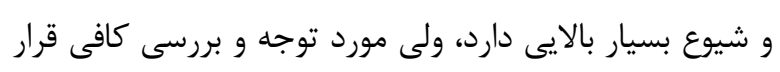

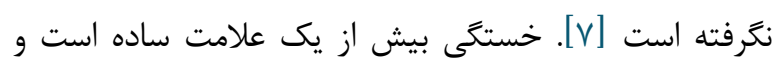

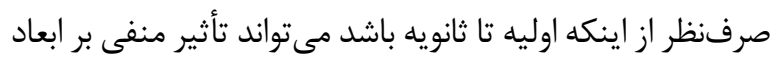

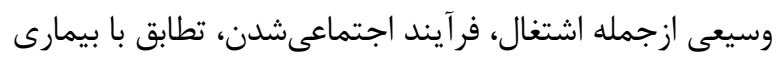

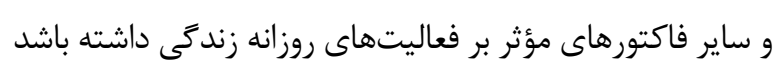

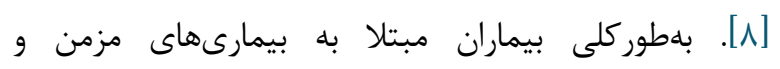

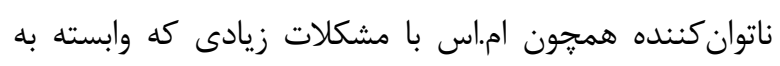

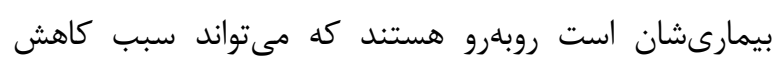

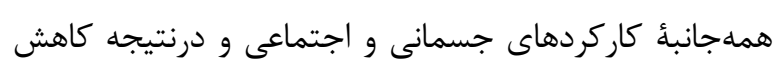
كيفيت زندگى آنان مىشود [1 [1] نيز معتقد بود بسيارى از افراد كه با بيمارى Dobryakova

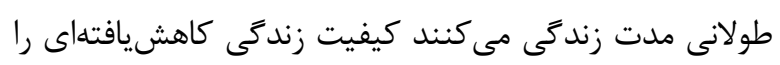

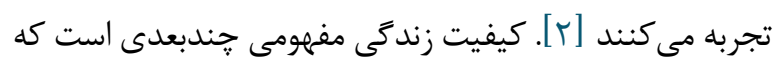

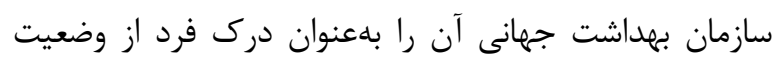

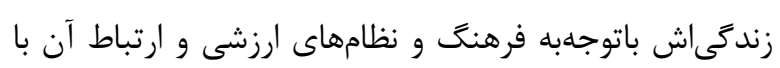

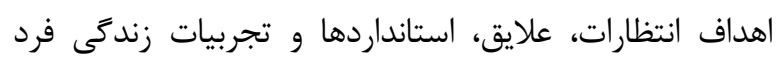


ملاحظات اخلاقى يزوهش حاضر به شح زير است: ا. به بيمار

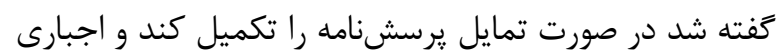

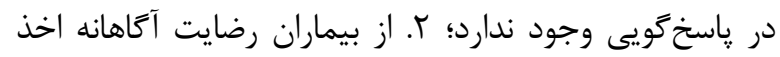

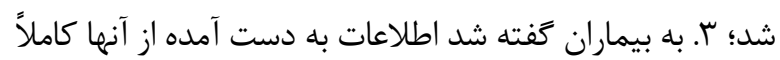

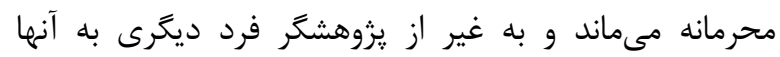

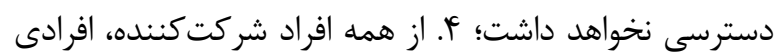

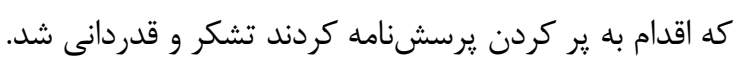

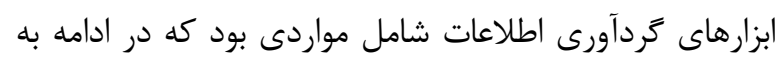
آنها اشاره شده است. مقياس شدت خستخى (FSS): اين مقياس

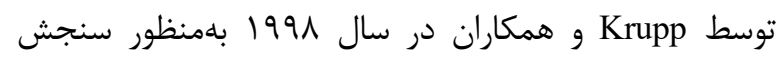

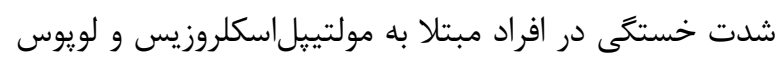

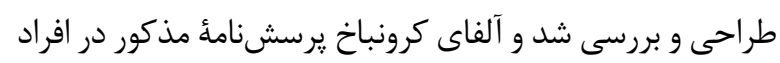

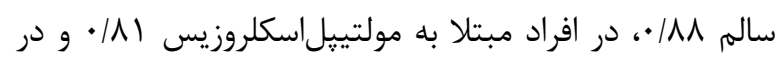

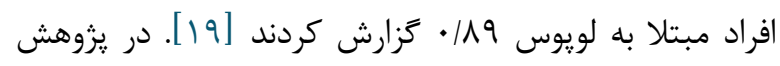

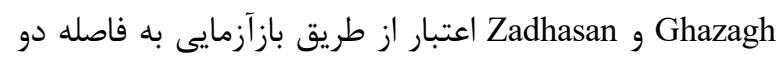

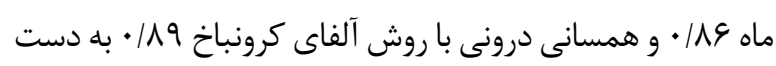

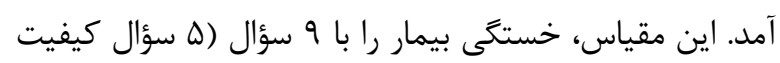

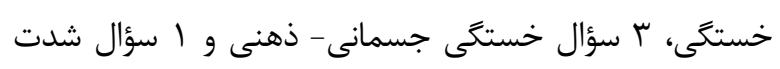

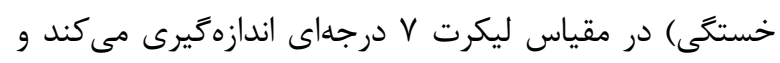

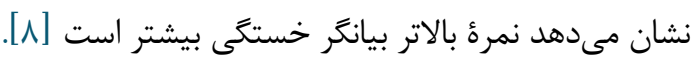

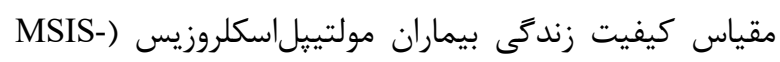

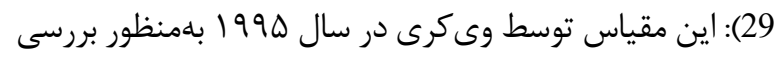

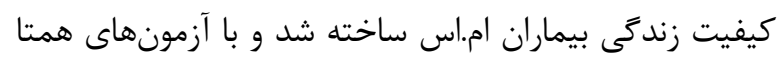

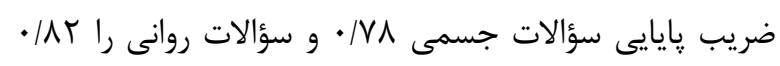

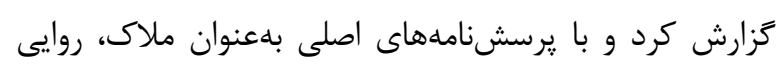

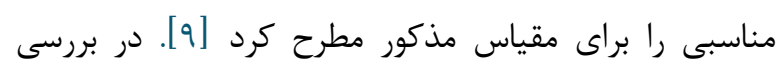

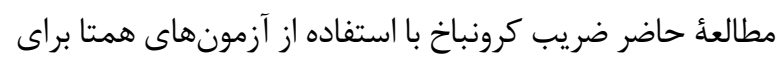

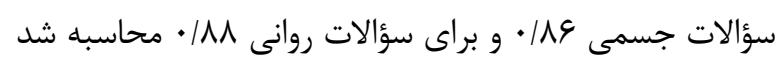

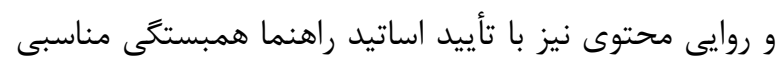

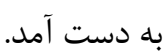

اين مقياس، كيفيت زندكى بيمار را با وج سؤال (•r سؤال اول

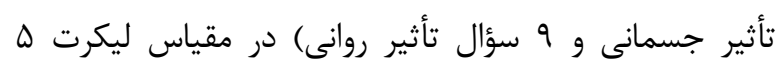

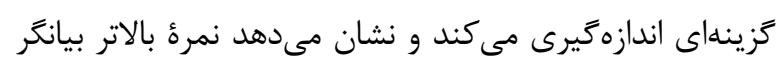
كيفيت زندگى گِائينتر است.

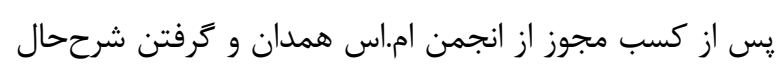

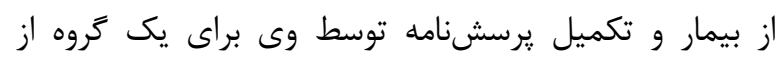

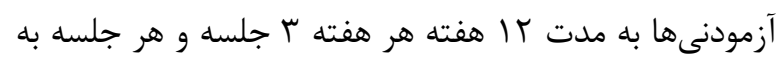

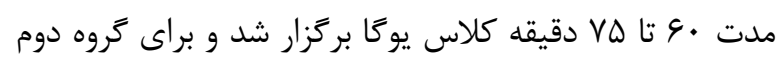

انعطافيذيرى وى افزايش يابد. در درمان مبتنى بر يذيرش و

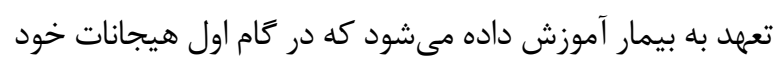

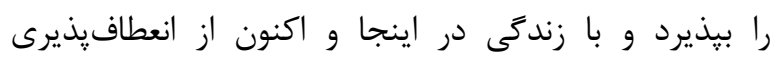

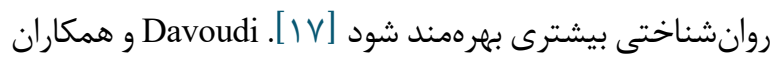

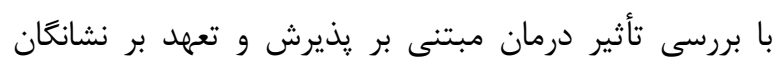

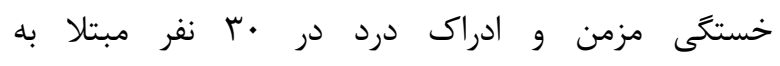

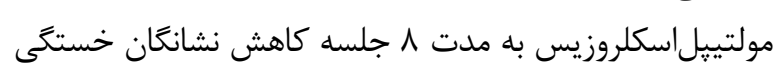

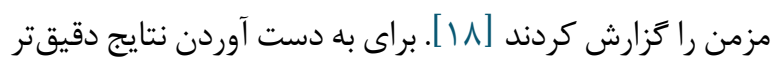

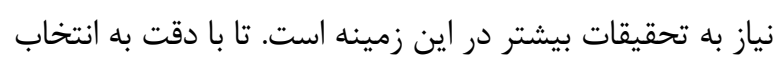

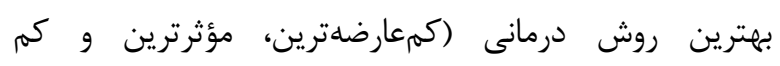

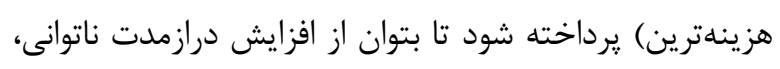

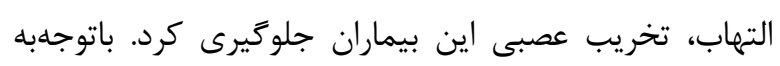

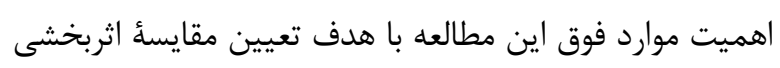

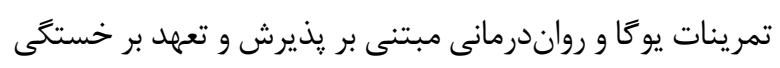
و كيفيت زندگى بيماران ام.اس انجام كرفت.

\section{روش كار}

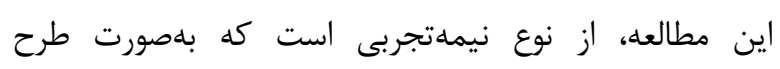

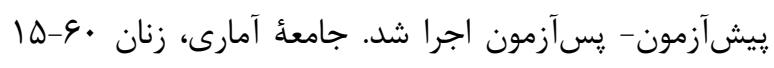

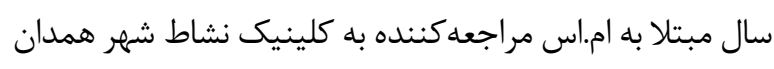

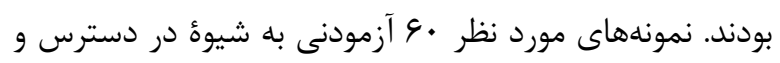

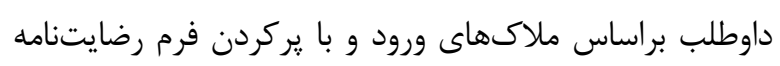

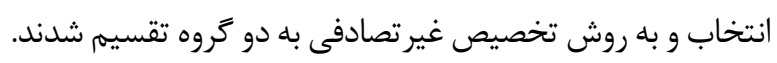

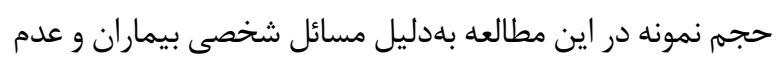

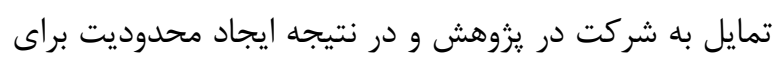

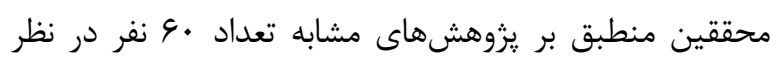

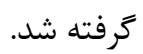
ملاكهاى ورود به مطالعه عبارت بودند از ا. تشخيص قطعى

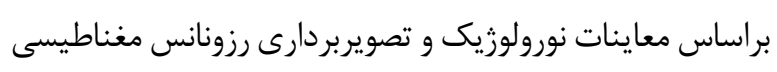

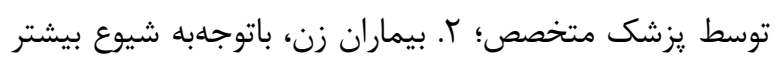

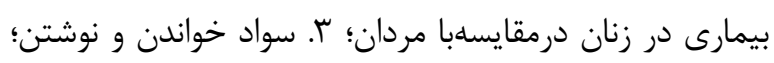

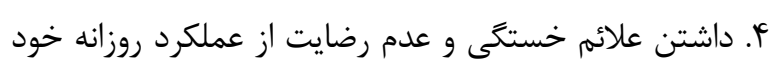

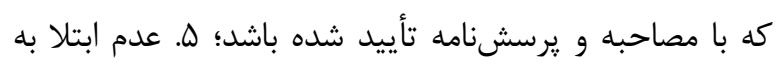

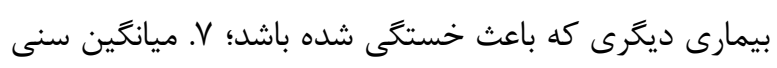

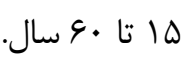

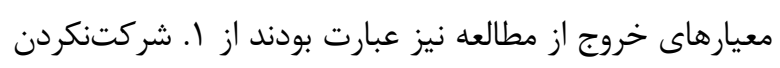

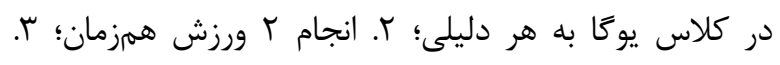

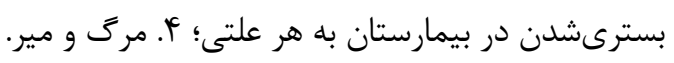




$$
\text { و در جدول آل محتواى جلسات درمانى كروهى مبتنى بر بذيرش }
$$

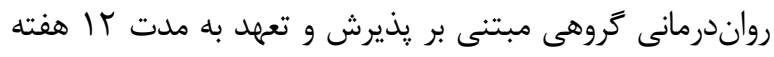

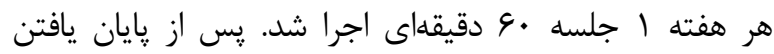

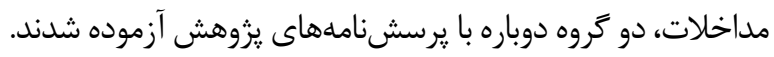

جدول ا. محتواى جلسات درمان گروهى مبتنى بر يذيرش و تعهد

\section{محتواى جلسه}

\section{جلسه}

برقرارى رابطهُ درمانى، آشناكردن افراد با موضوع يُوهش و درمان، پِاسخ به يُرسشنامه و بستن قرارداد درمان اول

كشف و بررسى روشهاى درمانى بيمار و ارزيابى ميزان تأثير آنها، بحث درمورد موقتىبودن و كماثر بودن آنها

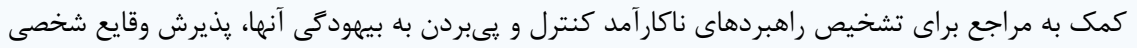

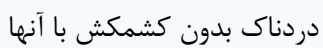

دوم

سوم

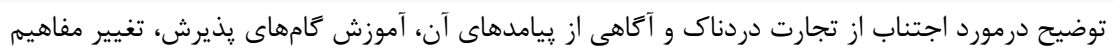

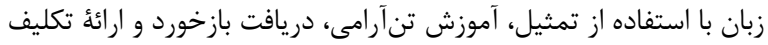

\section{جهارم}

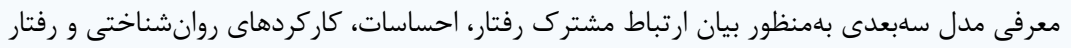

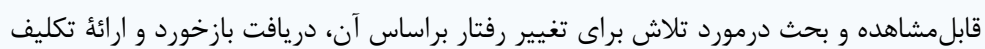

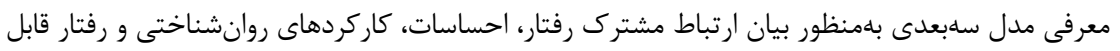

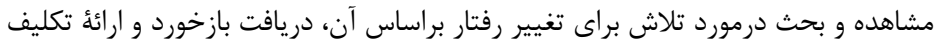

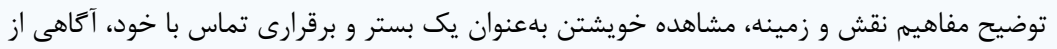

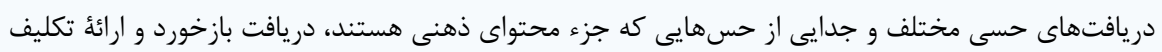

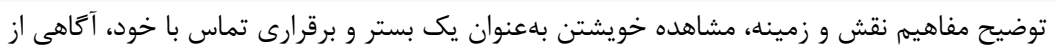
دريافتهاى حسى مختلف و جدايى از حسهايى كه جزء محتواى ذهنى هستند، دريافت بازخورد و ارائهُ تكليف

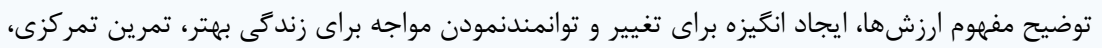

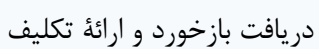

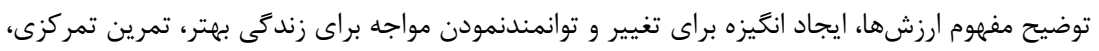
دريافت بازخورد و ارائهُ تكليف

\section{ينجم}

ششم

هفتم

هشتم

نקdo

دهم

يازدهم جلسات و اجراى پِ آز آزمون. آموزش تعهد به عمل، شناسايى طرحهاى رفتارى آنس مطابق با ارزشها و ايجاد تعهد براى عمل به آنها، جمعبندى جلسات و اجراى پِ آزمون.
موارد از آزمون آناليز كوواريانس و مقايسٔ جند گانهُ حداقل اختلاف معنى دار (LSD) استفاده شد.

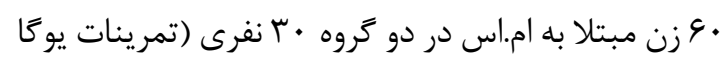

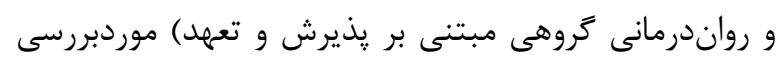

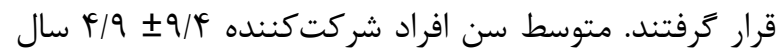
كه بهتفكيك در ورزش يوگا \&

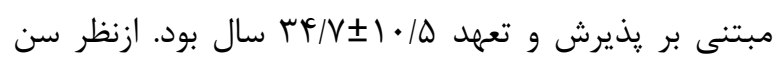

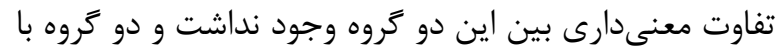
هم همخن بودند.

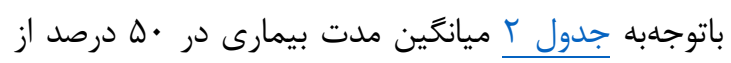

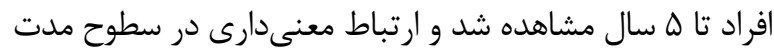

براى تحليل يافتهها از آزمون تى مستقل، كاى اسكور و آزمون دقيق فيشر، آناليز كوواريانس و LSD با سطح اطمينان

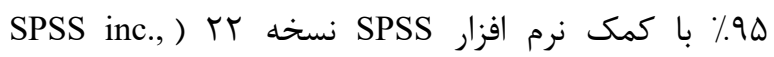
(Chicago, Ill., USA

\section{يافته ها}

براى مقايسهُ ويزگى هاى اوليهُ بيماران در دو گروه يوگًا و

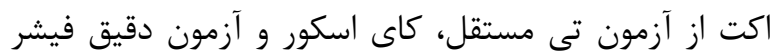

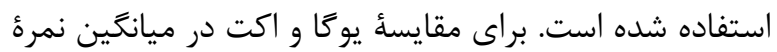
خستخى و كيفيت زندگى با در نظر گرفتن سطح اولئ اين 


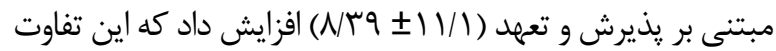

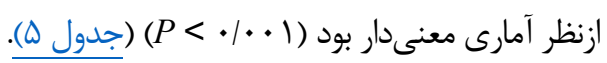

بلهطور كلى در بيمارانى كه يوكا انجام داده بودند درمقايسهبا

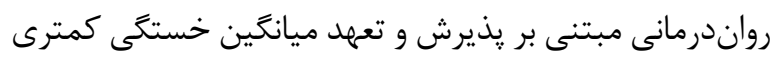

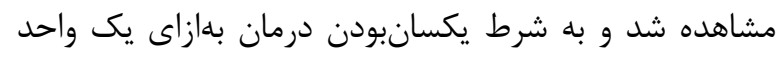
بيشتر بودن نمره خستخى قبل از درمان، ميانگين نمره

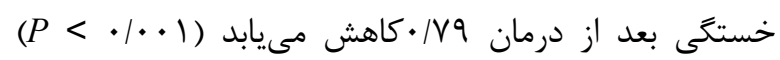

$$
\text { (تصوير (1) }
$$

همجنين بيمارانى كه يوگا انجام داده بودند درمقايسهبا

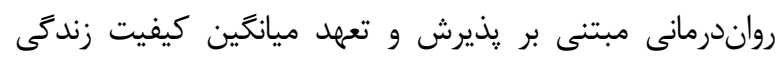

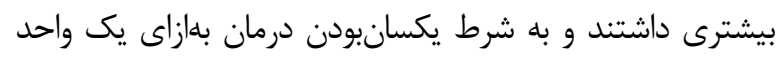
بيشتربودن نمرة كيفيت زندگى در قبل از درمان ميانگين نمرة

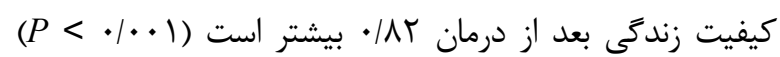

(تصوير ب).
زمان بيمارى و سابقه خانوادگى در گروههاى يوكا و اكت وجود

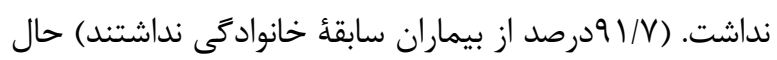
آنكه اين ارتباط در رابطه با تعداد علائم معنىىدار بود. جنانجه له. مشاهده مىشود بيشترين فراوانى تعداد علائم دو علامت در

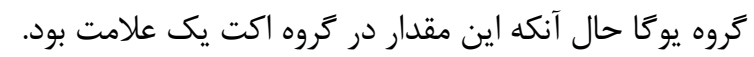

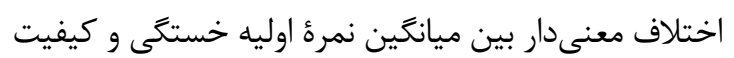

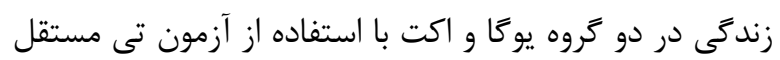

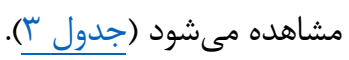

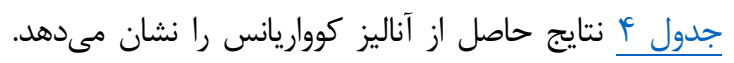
بررسى اثر درمان و نمرة خستخى اوليه بر نمرة خستخى و اثر درمان

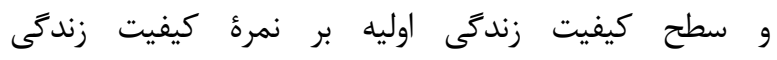

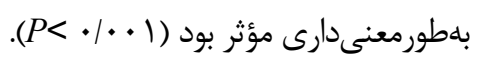

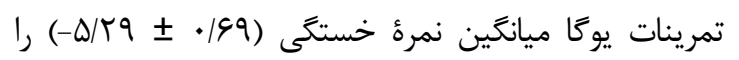
كاهش و ميانگين نمره كيفيت زندگى را درمقايسهبا رواندرمانى

جدول r. مقايسهُ ويزَّى تروههاى يوكا و رواندرمانى مبتنى بر يذيرش و تعهد

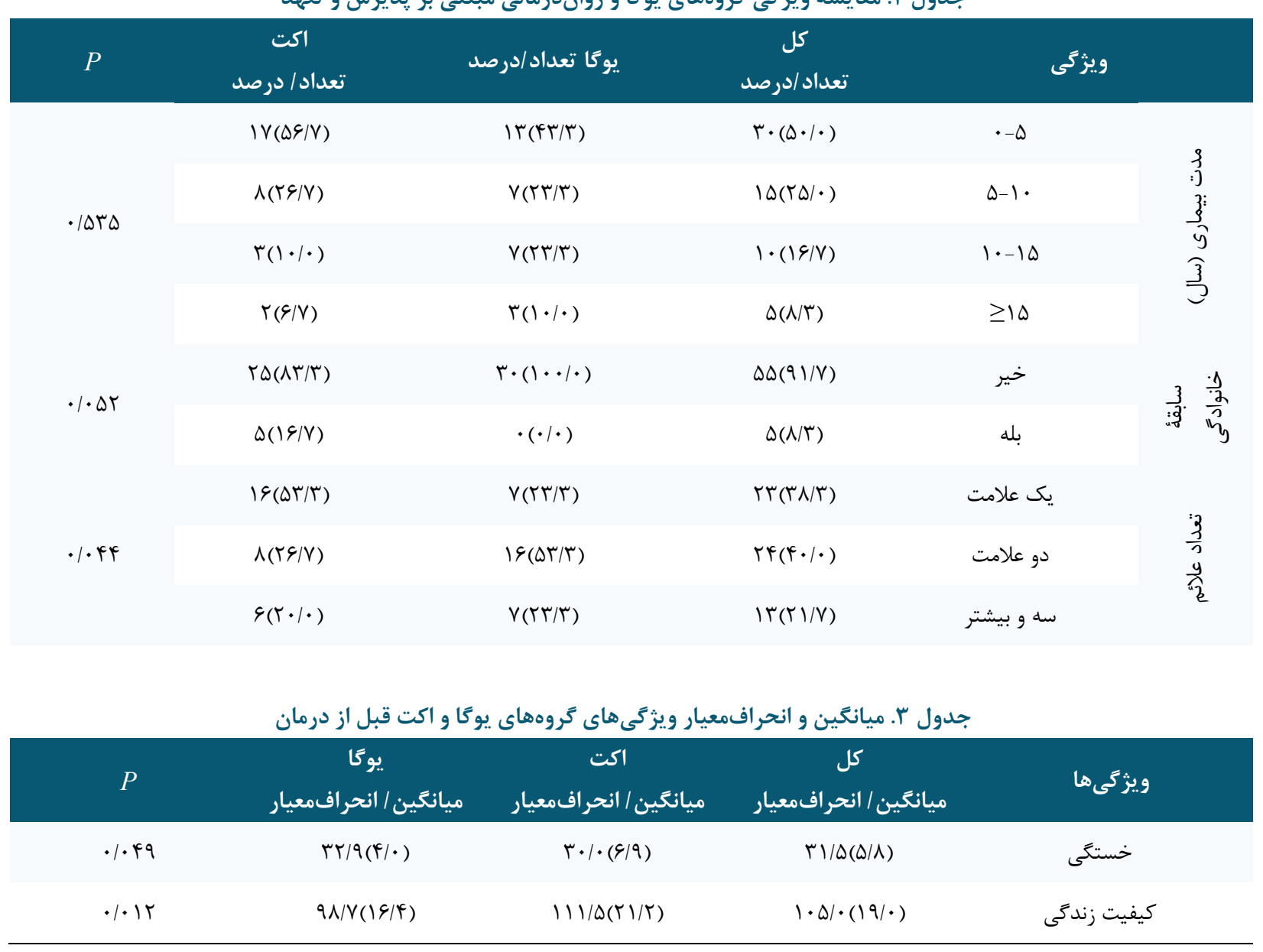


جدول F. جدول آناليز كوواريانس (اثر درمان بر نمره خستتى و كيفيت زندكى)

\begin{tabular}{|c|c|c|c|}
\hline$P$ & $\mathrm{~F}$ & درمان & ويزَّى \\
\hline$<\cdot 1 \cdot \cdot 1$ & $\Delta 9 / T \varphi$ & درمان & \multirow{2}{*}{ خستخى } \\
\hline$<\cdot \mid \cdot \cdot 1$ & $\mid \vee q / \cdot \Delta$ & خستخى اوليه & \\
\hline$<\cdot \mid \cdot \cdot 1$ & $\Delta \& / ৭ \&$ & درمان & \multirow{2}{*}{ كيفيت زندگى } \\
\hline$<\cdot / \cdot \cdot 1$ & $\Lambda F \Delta / V T$ & كيفيت زندگى اوليه & \\
\hline
\end{tabular}

جدول ه. مقايسةُ اختلاف ميانگين نمره خستخى و كيفيت زندكى براساس درمان

\begin{tabular}{|c|c|c|c|}
\hline$P$ & ميانتَين & ويزَّى & \\
\hline$<\cdot \mid \cdot \cdot 1$ & $-\Delta / r q(\cdot / 99)$ & خستكى & يوكا- اكت \\
\hline$<\cdot / \cdot \cdot 1$ & 1/rq $(1 / 11)$ & كيفيت زندكى & \\
\hline
\end{tabular}

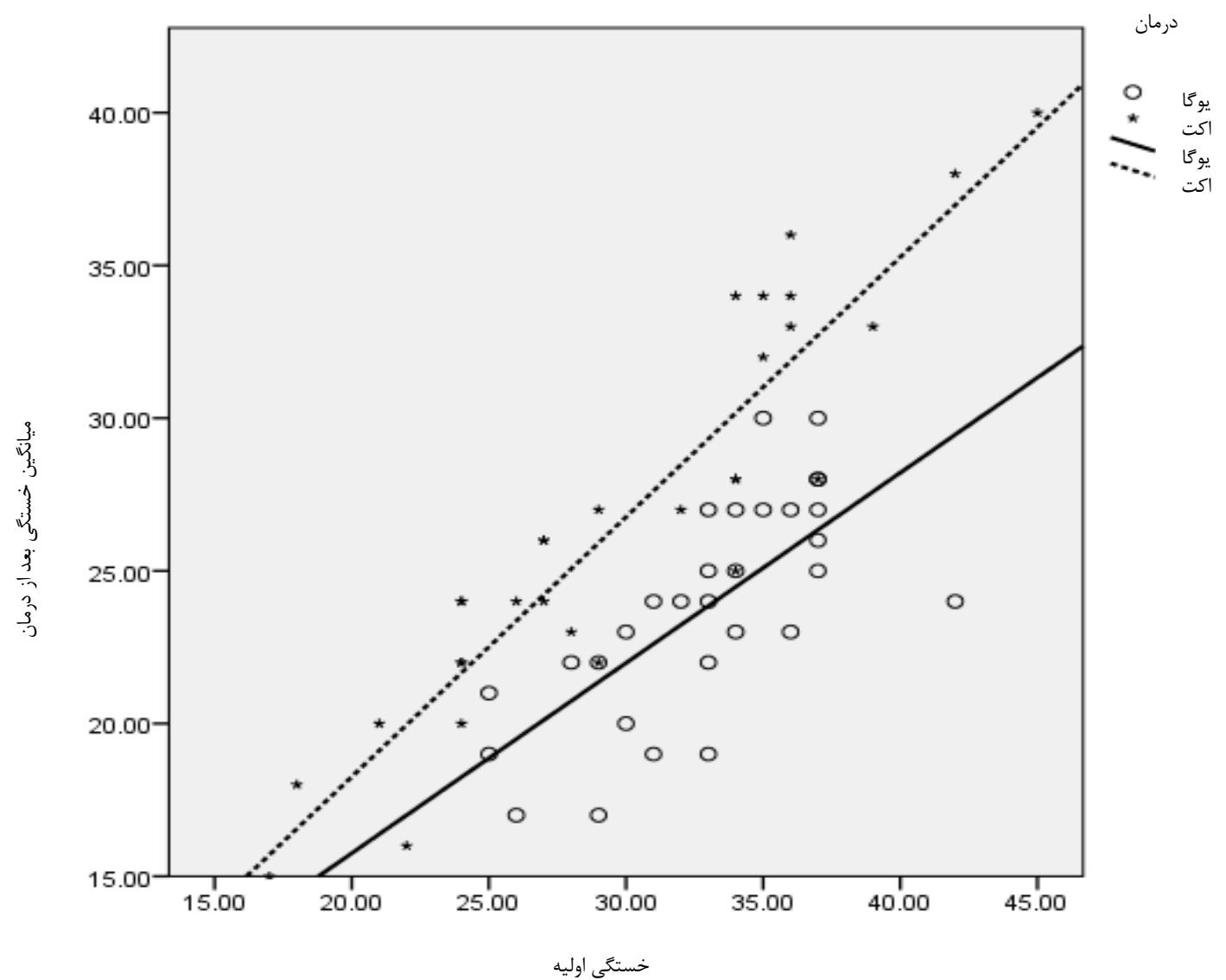

تصوير ا. ميانغَين خستخَى قبل و بعد از درمان إله 


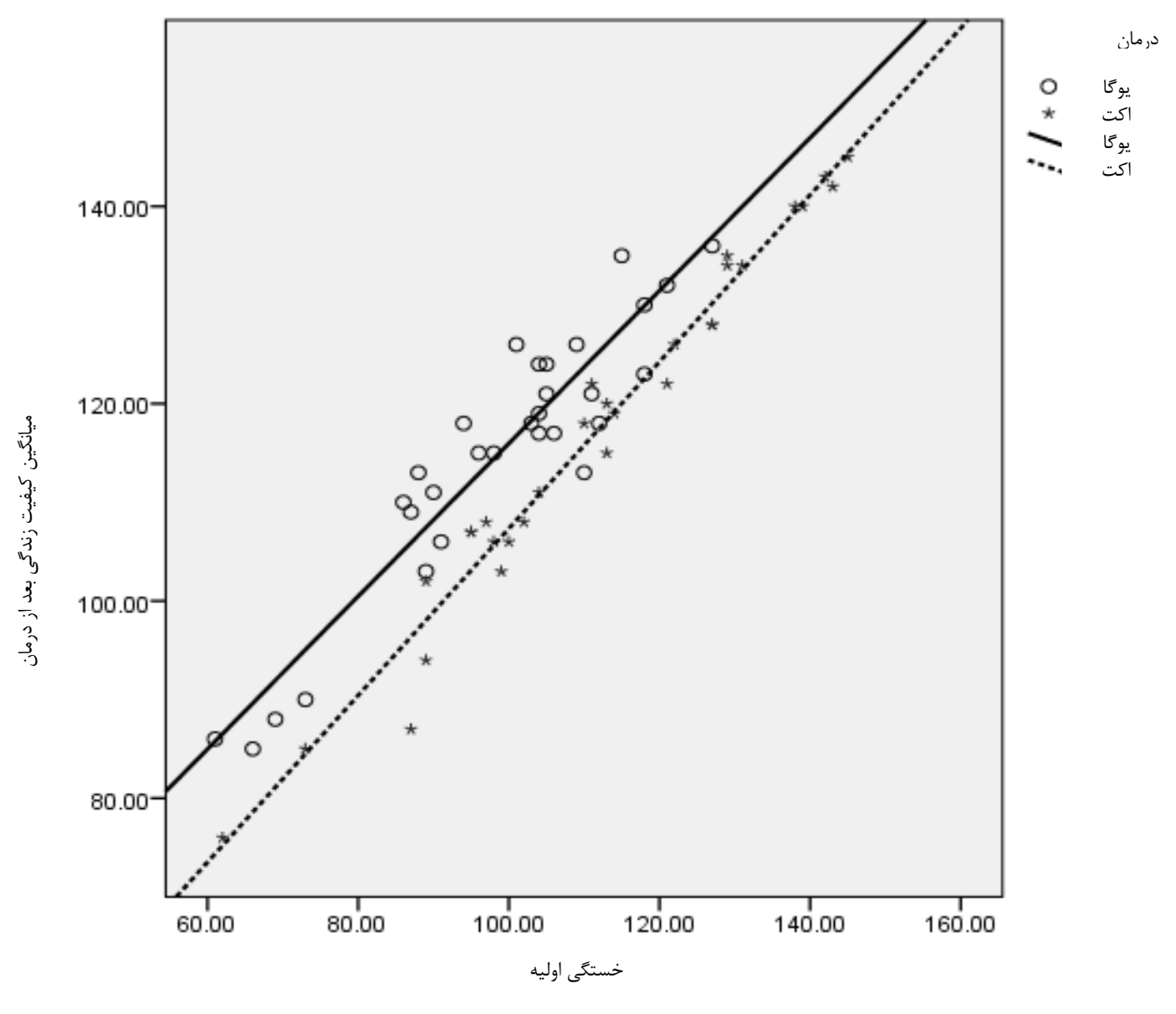

تصوير r. ميانگين كيفيت زندكى قبل و بعد از درمان

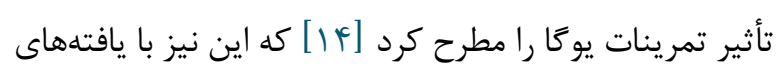

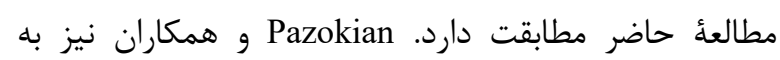
بررسى تأثير ورزشهاى كششى مطابقت بارد مدت 9 هفته بر ميزان

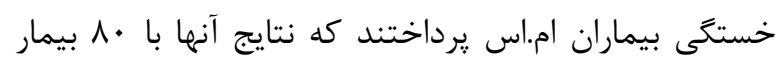

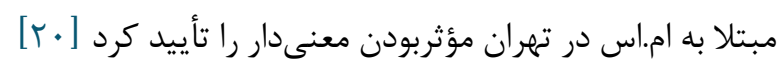

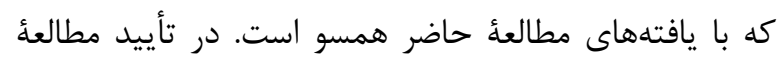

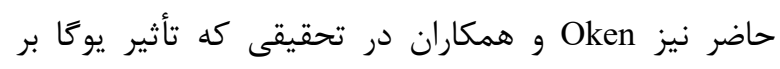

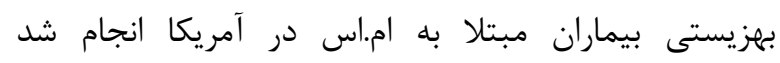

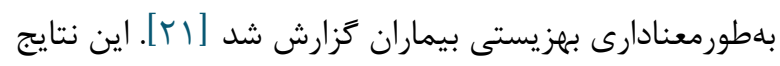

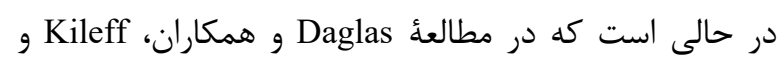

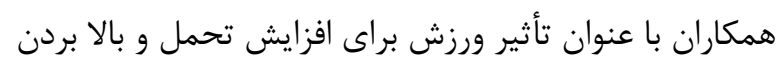

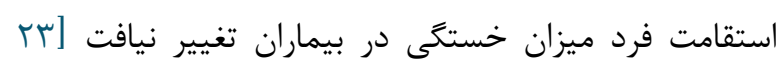
كrr.

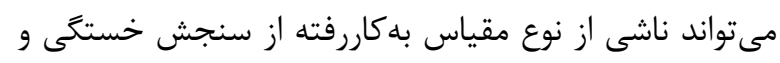

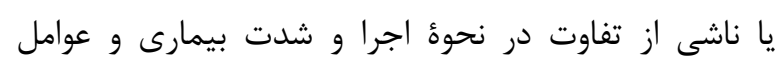

يزوهش حاضر با هدف بررسى مقايسٔ اثربخشى تمرينات

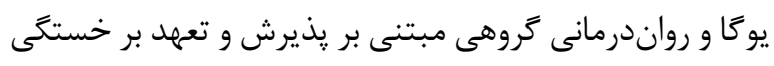

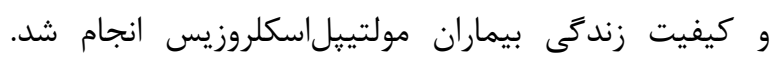

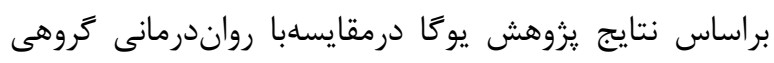

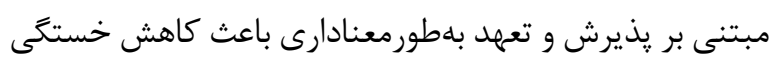

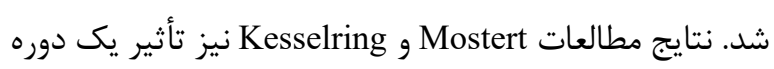

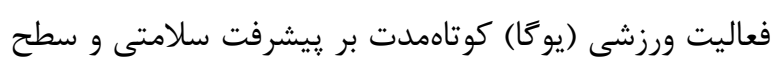

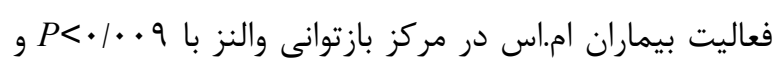

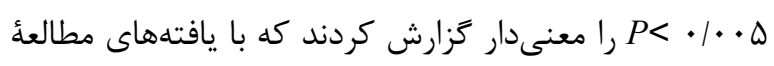

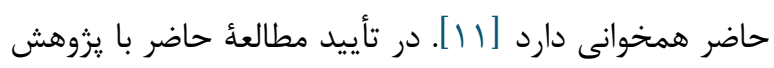

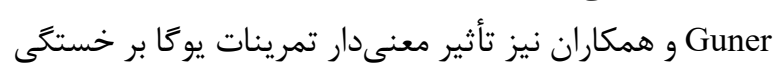

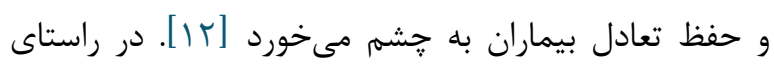

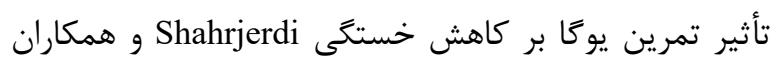

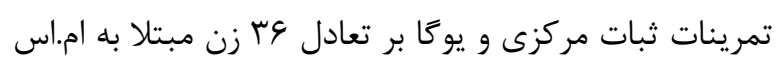

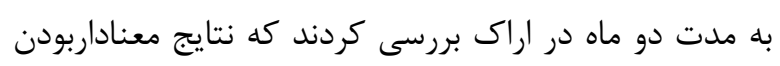


آزمودنىها زيرا ممكن است افراد هنغام تكميل يرسشنامهها

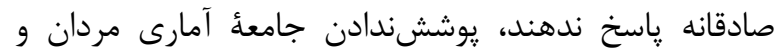
استفاده از نمونههاى در دسترس، و محدودشدن نمونهائ نائ

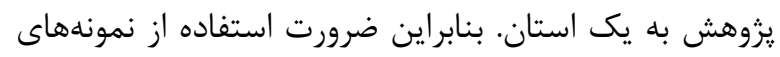

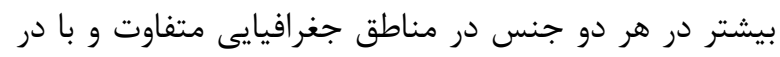

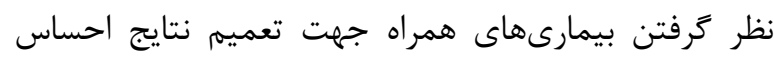
مىشود.

\section{نتيجه كيرى}

براساس نتايج يزوهش تمرينات يوزا درمقايسهبا

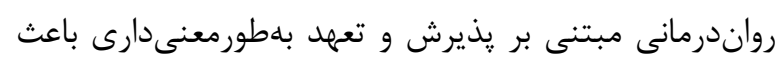

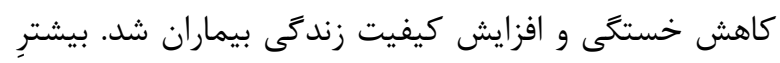

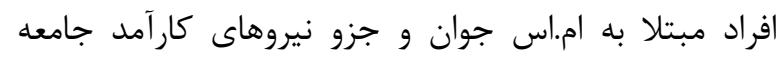

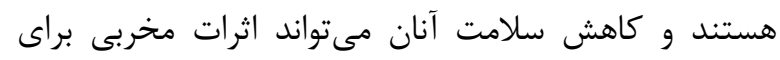

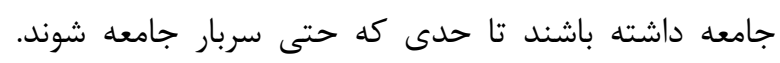

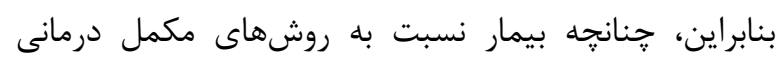

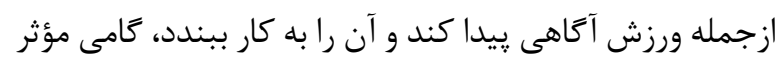
در بهبود سلامتى خويش برداشته است.

\section{سياسگز ارى}

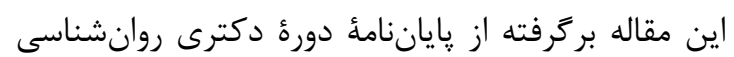

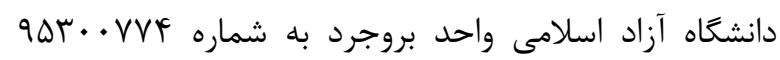

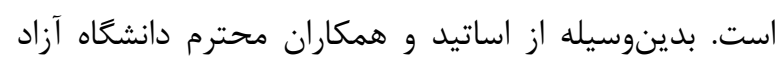

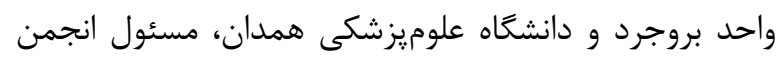

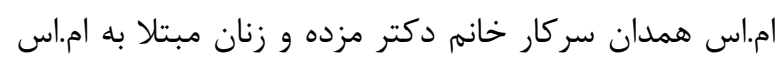

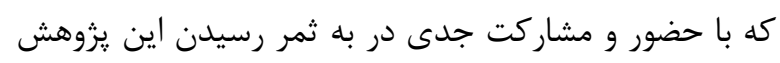

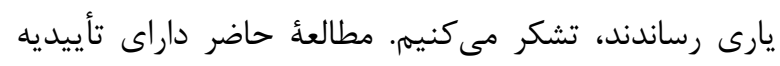

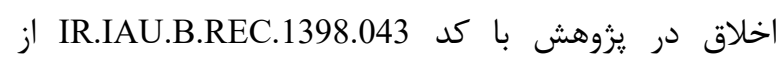

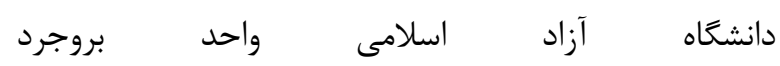

و (https://ethics.research.ac.ir/ProposalViewEn.php?id=107080) كار آزمايى بالينى با كد IRCT20200423047176N1 است.

$$
\text { تعارض در منافع }
$$

بين نويسندًان هيجَّونه تعارضى در منافع وجود ندارد

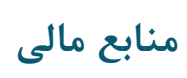

منابع مالى اين مطالعه توسط نويسندكان تامين شده است.
زمينهاى بيمارى باشد. ولى در تبيين نتايج كلى ميى توان كَفت

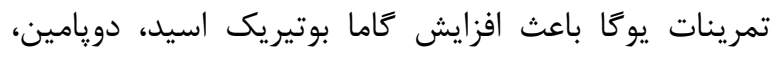

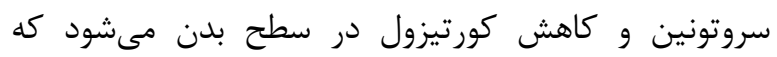

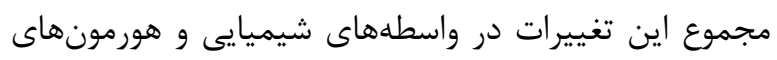

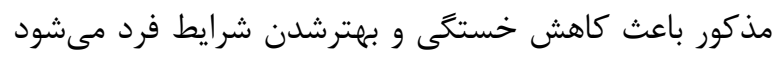

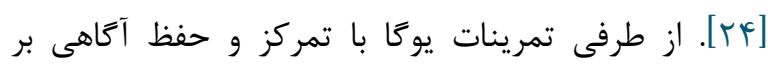

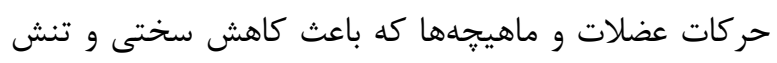

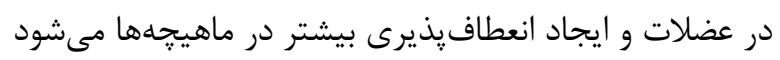

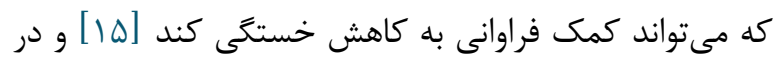

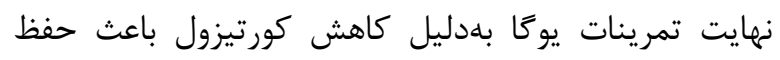

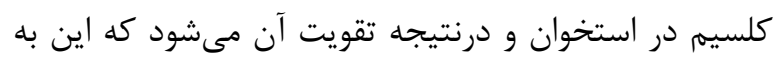

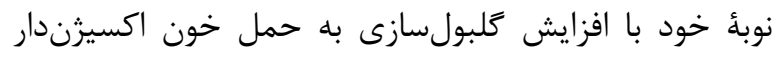

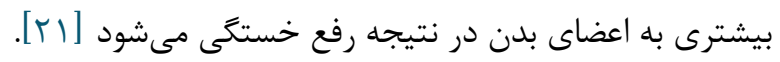

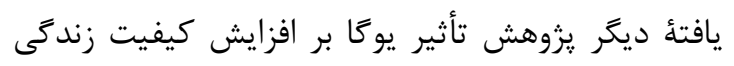

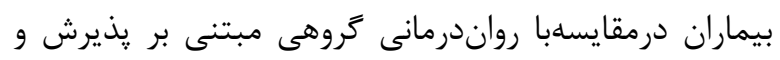

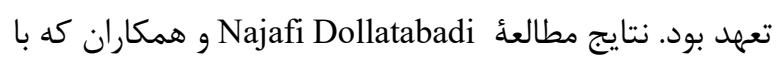

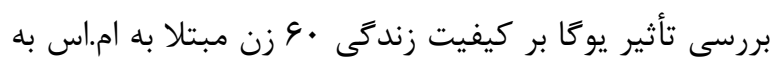

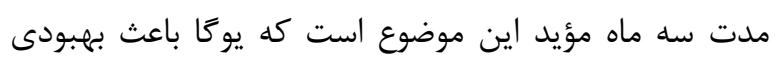

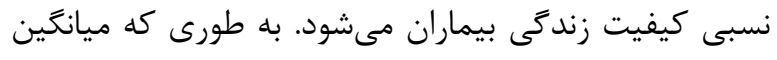

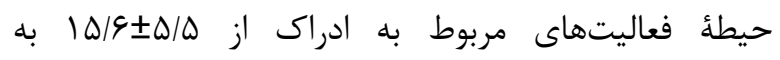
年 (P= مطالعة

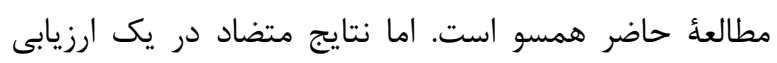

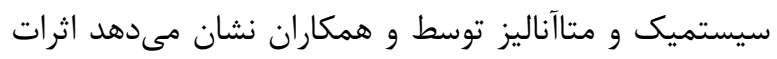

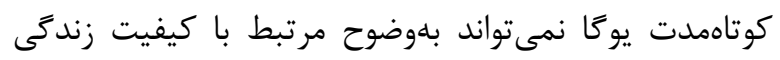

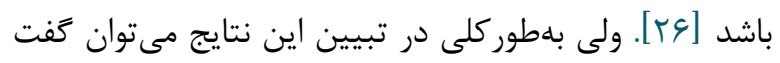

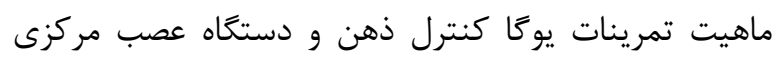

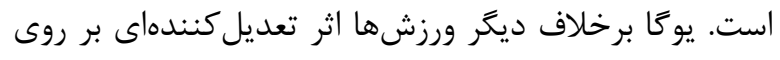

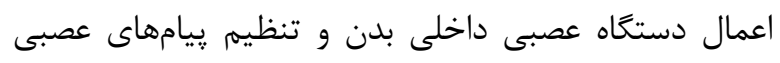

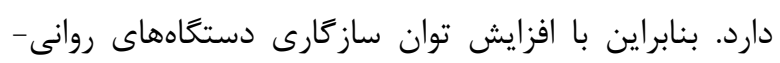

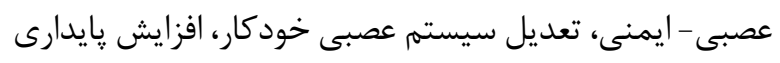

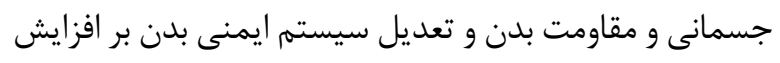

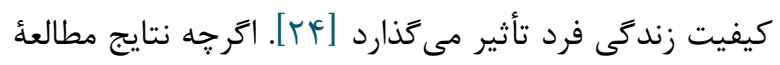

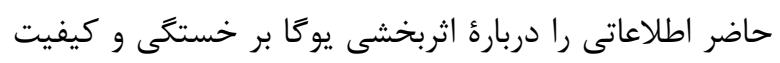

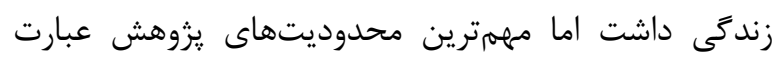

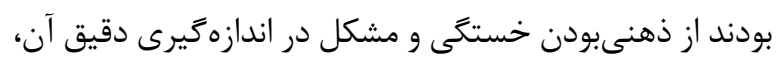

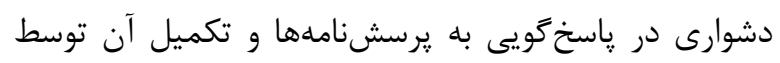




\section{References}

1. Janina Wendebourg MJ, Heesen C, Finlayson M, Meyer B, Pöttgen J, Köpke S. Patient education for people with multiple sclerosis-associated fatigue: a systematic review. PLoS One. 2017; 12(3):e0173025. [DOI:10.1371/journal.pone.0173025] [PMID] [PMCID]

2. Dobryakova E, Genova HM, DeLuca J, Wylie GR. The dopamine imbalance hypothesis of fatigue in multiple sclerosis and other neurological disorders. Front Neurol. 2015; 6:52. [DOI:10.3389/fneur.2015.00052] [PMID] [PMCID]

3. Cameron MH, Peterson V, Boudreau EA, Downs A, Lovera J, Kim E, et al. Fatigue is associated with poor sleep in people with multiple sclerosis and cognitive impairment. Mult Scler Int. 2014; 2014: 872732. [DOI:10.1155/2014/872732] [PMID] [PMCID]

4. Khabaronline. 70 Thousand MS Patients in Iran; 2017 [cited 2018 Feb. 2]. Available form: https://www.khabaronline.ir/detail/539288/society/he alth.

5. Induruwa I, Constantinescu CS, Gran B. Fatigue in multiple sclerosis-a brief review. J Neurol Sci. 2012; 323(1-2):9-15. [DOI:10.1016/j.jns.2012.08.007] [PMID]

6. Cote I, Trojan DA, Kaminska M, Cardoso M, Benedetti A, Weiss D, et al. (2013). Impact of Sleep Disorder Treatment on fatigue in Multiple sclerosis. $\begin{array}{lll}\text { Mult Scler. } & \text { 19(4):480-9. }\end{array}$ [DOI:10.1177/1352458512455958] [PMID]

7. Hasanpour-Dehkordi A, Jivad N, Solati K. Effects of yoga on physiological indices, anxiety and social functioning in multiple sclerosis patients: A randomized trial. Journal of clinical and diagnostic research: JCDR. 2016;10(6):VC01.

8. Ghazagh M, Zadhasan Z. The effet of Group Mindfulness- Based Stress Reduction Program on the Quality of Life and Fatigue in Patients With Multiple Sclerosis. Avicenna J Nurs Midwifery Care. 2019; 27(1): 35-44. [DOI:10.30699/ajnmc.27.1.35]

9. Kargarfard M, Eetemadifar M, Mehrabi M, Maghzi AH, Hayatbakhsh MR.Fatigue, Depression, and Health- Related Quality of Life in Patients with Multiple Sclerosis in Isfahan, Iran. Eur J Neurol. 2012; 19(3): 431-7. [DOI:10.1111/j.14681331.2011.03535.x] [PMID]

10. Salehpoor G, Rezaei S, Hosseininezhad M. Quality of life in Multiple Sclerosis (MS) and role of fatigue, depression, anxiety, and stress; A bicenter study from north of Iran. Iranian J Nurs Midwifery Res. 2014; 19(6): 593.

11. Mostert S, Kesselring J. Effects of a short-term exercise training program on aerobic fitness, fatigue, health perception and activity level of subjects with multiple sclerosis. Mult Scler. 2002; 8(2):161-8. [DOI:10.1191/1352458502ms779oa] [PMID]
12. Guner S, Inanici F. Yoga therapy and ambulatory multiple sclerosis assessment of gait analysis parameters, fatigue and balance. J Body Mov Ther. 2015; [DOI:10.1016/j.jbmt.2014.04.004] [PMID]

13. Aghili SM, Afzali S. The Effect of Yoga Yoga Breathing Exercises on chronic Low Pain, Anxiety, Psychological and Physical Well-being of Women with MS. Health Psych. 2017; 5(20):109-24.

14. Shahrjerdi SH, Golpaygani M, Faraji F, Masoumi M. The Effect of 8 Weeks of Central Stability and Yoga Exercises on the Balance of Women with Multiple Sclerosis. Razi J. 2015; 22(140):32-42.

15. Amaranath B, Nagendra HR, Deshpande S. Effect of integrated Yoga module on positive and negative emotions in Home Guards in Bengaluru: A wait list randomized control trial. Int J Yoga. 2016; 9(1):35. [DOI:10.4103/0973-6131.171719] [PMID] [PMCID]

16. Hawton, Salkovskis K. Cognitive theraphy for psychiatric problems. Translator? Tehran: Arjmand; 2011. p: 259-68.

17. Buhrman M, Skoglund A, Husell J, Bergström K, Gordh T, Hursti T, et al. Guided internet-delivered acceptance and commitment therapy for chronic pain patients: a randomized controlled trial. Behav Res Ther. 2013; 51(6):307-15. [DOI:10.1016/j.brat.2013.02.010] [PMID]

18. Davoudi M, Shamli L, Hasianfard H. The effect of treatment based on acceptance and commitment on the symptoms of chronic fatigue and pain perception of people with multiple sclerosis. Iran J Psychi Clin Psych. 2019; $250-265$. [DOI:10.32598/ijpcp.25.3.250]

19. Krupp LB, LaRocca NG, Muir-Nash J, Steinberg AD. The fatigue severity scale: application to patients with multiple sclerosis and systemic lupus erythematosus. Arch Neurol. 1989; 46(10):1121-3. [DOI:10.1001/archneur.1989.00520460115022] [PMID]

20. Pazokian M, Shaban M, Zakerimoghadam M, Mehran A, Sangalji B. The effect of aerobic stretching exercise on fatigue in patients with MS referred to MS Society of Tehran. J Hol Nurs Midwifery; 2012, 22(2): 18-24.

21. Oken B, Kishigams S, Zajdel D, Bourdette D, Carlsen J, Hass M et all. Randomized Controlled trial of Yoga and Exercise in Multiple Sclerosis. J Neurol. 2004. 62(11):2058-64.

doi:

10.1212/01.wnl.0000129534.88602.5c [DOI:10.1212/01.WNL.0000129534.88602.5C] [PMID]

22. Daglas U, Stenager E. "Ingemann- Hansen T. Multiple Sclerosis and Physical Exercise: Recommendation for the application ofresistance- endurance- and combined training effects of Yoga on symptom management in breast cancer patients: A randomized controlled trail. Int J Yoga. 2008; 2(2):73-9. 
23. Kileff J, Ashburn A. A pilot study of the effect of aerobic exercise on people with moderate disability Multiple Sclerosis. Clin Rehab. 2005; 19(2): 165-9. [DOI:10.1191/0269215505cr839oa] [PMID]

24. Velikonja O, Curic K, Ozura A, Jazbec SS. Influence of sports climbing and yoga on spasticity, cognitive function, mood and fatigue in patients with multiple sclerosis. Clin Neurol Neurosurg. 2010; 112(7): $597-$ 601. [DOI:10.1016/j.clineuro.2010.03.006] [PMID]

25. Najafi Dollatabadi $\mathrm{SH}$, Nourian $\mathrm{KH}$, Najafi Dollatabadi A, Mohhebi Z. The effect of yoga techniques on the quality of life of women with multiple sclerosis. Hormozgan Med J. 2012; 16(2):143-150.

26. Cramer H, SilkeLangs P, Klose P, Paul A, Dobos G. Yoga for breast cancer patients and survivors: a systematic rewiew and meta- analysis. BMC Cancer; 2012; 12: 412. [DOI:10.1186/1471-2407-12-412] [PMID] [PMCID] 